\title{
ASPECTOS DA ECONOMIA DA INFORMAÇÃO: ARQUÉTIPO CONCEITUAL ECONÔMICO E SOCIAL
}

\author{
ASPECTOS DE LA INFORMACIÓN ECONÓMICA: \\ ARQUETIPO CONCEPTUAL ECONOMICO Y SOCIAL
}

\author{
Fábio Corrêa* \\ Jurema Suely de Araújo Nery Ribeiro** \\ Marta Macedo Kerr Pinheiro***
}

\begin{abstract}
RESUMO:
Introdução: As empresas passaram por significativas mudanças advindas de paradigmas evolutivos amparados por aspectos tecnológicos e informacionais, que provocaram transformações diversas tornando o ambiente, interno e externo, das organizações complexo devido ao intricado rompimento de padrões na evolução da sociedade, no qual informação, competição e tecnologia possuem atuação determinante. Objetivo: Este estudo objetivou promover uma reflexão acerca dos aspectos da economia da informação que determinam esta nova sociedade, norteando-se pela problemática: quais aspectos subvertedores fundamentam a economia da informação? Metodologia: Trata-se de uma pesquisa exploratória, por buscar uma ótica dilatada da economia da informação, a fim de proporcionar compreensão e reflexão sobre seus aspectos subversores; e descritiva por objetivar elucidar, pela análise e interpretação dos fatos, as dimensões da economia da informação. Resultados: Como resultado foi proposto um arquétipo conceitual dos aspectos subvertedores da economia da informação, representados pelas dimensões produção, pessoas, finanças, organização, ciência e mercado. Conclusão: Conclui-se que este estudo tende a contribuir para a compreensão e reflexão dos aspectos relacionados à economia da informação, por meio da comparação com as eras da sociedade, oferecendo assim uma visão ampla desta economia.
\end{abstract}

Palavras-chave: Economia da informação. Economia do conhecimento. Aspectos subvertedores. Arquétipo conceitual.

*Doutorando em Sistemas de Informação e Gestão do Conhecimento pela Universidade FUMEC. E-mail fabiocontact@gmail.com

**Doutoranda em Sistemas de Informação e Gestão do Conhecimento pela Universidade FUMEC. E-mail jurema.nery@gmail.com

***Doutora em Ciência da Informação. Professora do Programa de pós-Graduação em Sistemas de Informação e Gestão do Conhecimento da Universidade Fumec-MG e Professora Colaboradora do Programa de Pós-Graduação em Gestão e organização do Conhecimento da Universidade Federal de Minas Gerais. E-mail marta.macedo@fumec.br 
Fábio Corrêa, Jurema Suely de Araujo Nery Ribeiro, Marta Macedo Kerr Pinheiro Aspectos da economia da informação: arquétipo conceitual econômico e social

\section{INTRODUÇÃO}

As empresas passaram por vultosas mudanças oriundas de paradigmas evolutivos, amparados por aspectos tecnológicos e informacionais, que provocaram transformações tornando complexo o ambiente, interno e externo, das organizações, devido ao intricado rompimento de padrões na evolução da sociedade no qual a informação, competição e tecnologia possuem atuação determinante (LÉVY, 2001; PREVEDELLO; ROSSI; COSTA, 2015).

As pessoas, enquanto geradoras de conhecimento e ativos, constituem as empresas (SVEIBY, 1998; TINOCO, 2005; STEWART, 2007; PEREZ; FAMÁ, 2015) e são influenciadas pelas alterações socioeconômicas. Consequentemente, as organizações se adequam a tais mutações promovendo alterações no processo produtivo em prol da competitividade (CASTELLS, 2007).

A nova lógica do poder mundial se baseia em competência e confrontação, bem como, a combinação de diversos mecanismos de poder nos campos militar, econômico, político, cultural e ideológico. O componente estratégico fundamental passa a ser o controle da tecnologia de ponta, da força de trabalho barata e, ou, qualificada, e dos recursos essenciais. A liderança tecnológica define a condição de hegemonia dos Estados e dos Capitais, já que através dela são impostos os padrões gerais de reprodução e multiplicação dos ganhos tecnológicos (DUPAS, 2005).

Herbert Simon, citado por Shapiro e Varian (2013, p.6), enfatiza que "a riqueza da informação cria a pobreza da atenção". De fato, o volume informacional tende a dispersão de foco e sobrecarga. A sobrecarga relacionase aos decorrentes avanços tecnológicos que têm proporcionado aumento no número de dispositivos que tratam a informação. Desta forma, a ciência busca compreender como a informação é transmitida, como pode ser armazenada e como pode ser usada para a tomada de decisão.

Esta relação de transformações da sociedade e das organizações, alicerçadas na tecnologia e amparadas pelas ciências, advém da importância da informação e do conhecimento na era cunhada por Drucker (1999) como sociedade pós-capitalista, na qual a economia se fundamenta na informação. 
Fábio Corrêa, Jurema Suely de Araujo Nery Ribeiro, Marta Macedo Kerr Pinheiro Aspectos da economia da informação: arquétipo conceitual econômico e social

Segundo Petit (2005), a economia baseada no conhecimento refere-se a uma situação na qual os agentes econômicos, ou seja, qualquer entidade que pertence e atua num determinado sistema econômico - empresa, cooperativa, órgão governamental - têm a sua disposição um volume significativo de informação e conhecimento.

Diante deste volume informacional, o processamento, armazenamento e comunicação tendem a possibilitar o alcance estratégico, porém países e agentes econômicos nem sempre possuem condições de se beneficiarem desta situação, pois existem diversos problemas organizacionais que devem ser solucionados (PETIT, 2005).

Desta forma, este estudo busca promover uma reflexão acerca dos aspectos da economia da informação que determinam esta sociedade, norteando-se pela problemática: quais aspectos subvertedores fundamentam a economia da informação?

Neste sentido, a pesquisa caracteriza-se como exploratória descritiva. Exploratória por buscar uma ótica dilatada da economia da informação, a fim de proporcionar compreensão e reflexão sobre seus aspectos subversores, pois, de acordo com Gil (1999), este tipo de pesquisa busca uma visão amplificada sobre determinado fato, visando seu entendimento; e descritiva por objetivar descrever características de determinado fenômeno, pela análise e interpretação dos fatos (GIL, 1999; COSTA; COSTA, 2001).

Conforme pesquisa realizada em junho de 2016, na base SPELL (título e palavra-chave) e SCIELO (todos os índices) sobre os termos "economia da informação OU economia do conhecimento", foram obtidas 1 e 8 publicações, respectivamente, que não contemplam economia da informação como temática central. Desta forma, este estudo se justifica por promover uma ótica orientada aos aspectos da economia da informação, por meio de uma visão expandida.

\section{DESENVOLVIMENTO}

\subsection{Rupturas da sociedade, aspectos econômicos e sociais}

O termo economia admite diversas acepções como o uso de recursos ou valores, exemplificado pela contenção de gastos que gera acumulo de valores como quando um indivíduo efetiva uma aquisição com menor dispêndio que o 
Fábio Corrêa, Jurema Suely de Araujo Nery Ribeiro, Marta Macedo Kerr Pinheiro Aspectos da economia da informação: arquétipo conceitual econômico e social

esperado, ou pelo ganho pecuniário em detrimento do emprego de atividades que resultam no rendimento em dinheiro, ou pela ciência que se orienta pelo estudo do ganho pecuniário (SINGER, 2002).

No que tange esta proposta, compreende-se economia pelo ganho pecuniário, ou seja, as formas de ganhos de capital (dinheiro) sobre atividades empregadas para este fim. Neste quesito a economia da informação e do conhecimento (EIC) apresenta-se como uma economia de ruptura dos padrões oriundos das eras anteriores.

Para contextualizar a EIC torna-se relevante remontar cenários anteriores nos quais outras formas de ganho de capital imperavam, permitindo assim demonstrar a quebra de paradigma para a EIC, sendo estes cenários aludidos pela visão de Toffler (1998), que ambienta a sociedade em ondas de transformação.

Toffler (1998) acena que a sociedade evoluiu em ondas que perpassam a agricultura, indústria e serviços. Estas ondas são caracterizadas por revoluções, demonstrando que tais mudanças afetam não somente os meios econômicos - de geração de riquezas - mas também os indivíduos e a sociedade.

A sociedade primitiva foi suplantada pela Revolução Agrícola (primeira onda), na qual incidiu a divisão simples do trabalho e a organização em aldeias, tendo a terra como a base da economia por meio do cultivo do solo, sendo a produção para uso próprio (TOFFLER, 1998). A energia de propulsão era humana, animal e eólica, e a tecnologia ascendera para o uso do plaustro, rodas d'agua, barcos, dentre outros (PEREIRA, 1995).

A Revolução Agrícola, que permeia o período de 1650 a 1750 D.C., já apresentava atividades comerciais com fins econômicos como trocas, rotas comerciais de navegação, dinheiro e câmbio, companhias incipientes, surgimento de metrópoles (TOFFLER, 1998) e o projeto de máquina a vapor de James Watt (TOFFLER, 1998; HOBSBAWM, 2015). A agricultura era o meio de geração de capital, tendo por insumo econômico a terra.

Em apreço as palavras de Hobsbawm (2015, p. 5), a Revolução Industrial (segunda onda) "[...] foi porventura o acontecimento mais importante da história mundial, pelo menos desde a invenção da agricultura e das 
Fábio Corrêa, Jurema Suely de Araujo Nery Ribeiro, Marta Macedo Kerr Pinheiro Aspectos da economia da informação: arquétipo conceitual econômico e social

cidades", sustentando o surgimento de indústrias, permitindo a produção padronizada, instituindo polos industriais, novas tecnologias como as máquinas a vapor e o uso do carvão como combustível motor, inserindo máquinas na agricultura, criando ferrovias, carros, aviões, dentre outras inovações (TOFFLER, 1998; PEREIRA, 1995; HOBSBAWM, 2015).

A Revolução Industrial, datada em 1760 (TOFFLER, 1998; HOBSBAWM, 2015), subverteu a sociedade agrícola de uma economia baseada na terra para uma economia baseada no capital. O novo paradigma de produção e consumo eleva o capital ao status de elemento propulsor da economia, baseada em bens tangíveis.

Enquanto na primeira onda as pessoas produziam para consumo, na segunda onda a produção é orientada para o consumo de outrem (mercado). Obviamente, ambas possuíram características de consumo. A era da agricultura produzia principalmente para uso próprio, mas também havia comercialização desta produção. Em recíproca a indústria se alicerça na produção para o mercado, entretanto há produção para consumo como na primeira onda (TOFFLER, 1998).

Conseguinte, a Era da Informação e Conhecimento (terceira onda) apresenta-se com registros de 1973, no qual Bell et al. (1973) alcunhou-a como "Sociedade Pós-Industrial". Em verdade, diversas denominações são apresentadas para esta onda sem consenso (ANGELONI; FERNANDES, 2000), como "Nova Sociedade", ou "Era dos Serviços" (TOFFLER, 1998), "Sociedade Pós Capitalista" (DRUCKER, 1999) e "Revolução da Informação" (STEWART, 2007).

A Revolução da Informação é fundamentada no conhecimento e comunicação como fonte de riqueza (STEWART, 2007). Observam-se três terminologias apresentadas nesta afirmação que são merecedoras de reflexão por suas relevâncias nesta onda: informação, conhecimento e comunicação.

A informação é compreendida como elemento imbricado de relevância, propósito e subjetividade (DRUCKER 1999; DAVENPORT; PRUSAK, 1998, SETZER, 1999), que por sua vez é transformado em conhecimento por meio do processo cognitivo do indivíduo, sedimentado em sua razão, reflexão, 
Fábio Corrêa, Jurema Suely de Araujo Nery Ribeiro, Marta Macedo Kerr Pinheiro Aspectos da economia da informação: arquétipo conceitual econômico e social

crenças e experiências (DAVENPORT; PRUSAK, 1998; CHOO, 2003; VALENTIM, 2013).

Destarte, a informação é insumo para o conhecimento que é gerado por pessoas. Neste âmbito, as pessoas são o principal ativo da empresa, pois todos os ativos e a estrutura organizacional são resultados de ações humanas e dependem dos indivíduos para continuar a existir (SVEIBY, 1998).

A comunicação adentra nesta era como meio potencializador para transmissão da informação e conhecimento, por meio da tecnologia, sendo esta o agente impulsionador da Era da Informação e Conhecimento. As Tecnologias da Informação e Comunicação (TIC) subsidiaram esta era e promovendo o surgimento de novos negócios como os comércios eletrônicos Business to Business (B2B), Business to Consumer (B2C), Consumer to Consumer ( $\mathrm{C} 2 \mathrm{C})$ e Business to Employee (B2E) -, empresas tecnológicas (Netscape, IBM, Microsoft e Apple), dentre outras (LAUDON; LAUDON, 2010; STEWART, 2007; TURBAN et al, 2010; RAINER JR; CEGIELSKI, 2011).

Assim, a ruptura da Revolução da Informação, ou Era da Informação e do Conhecimento, em relação à Revolução Industrial está na fonte de geração de riqueza do tangível para o intangível. Na sociedade da Revolução Agrícola, a fonte de riqueza era a terra (tangível), enquanto na Revolução Industrial tornou-se o capital financeiro (tangível), sendo este modificado na Revolução da Informação pelo elemento informacional (intangível), seja por sua posse, acesso ou controle dos meios de comunicação.

Figura 1 - Rupturas econômicas e sociais das ondas de evolução da sociedade

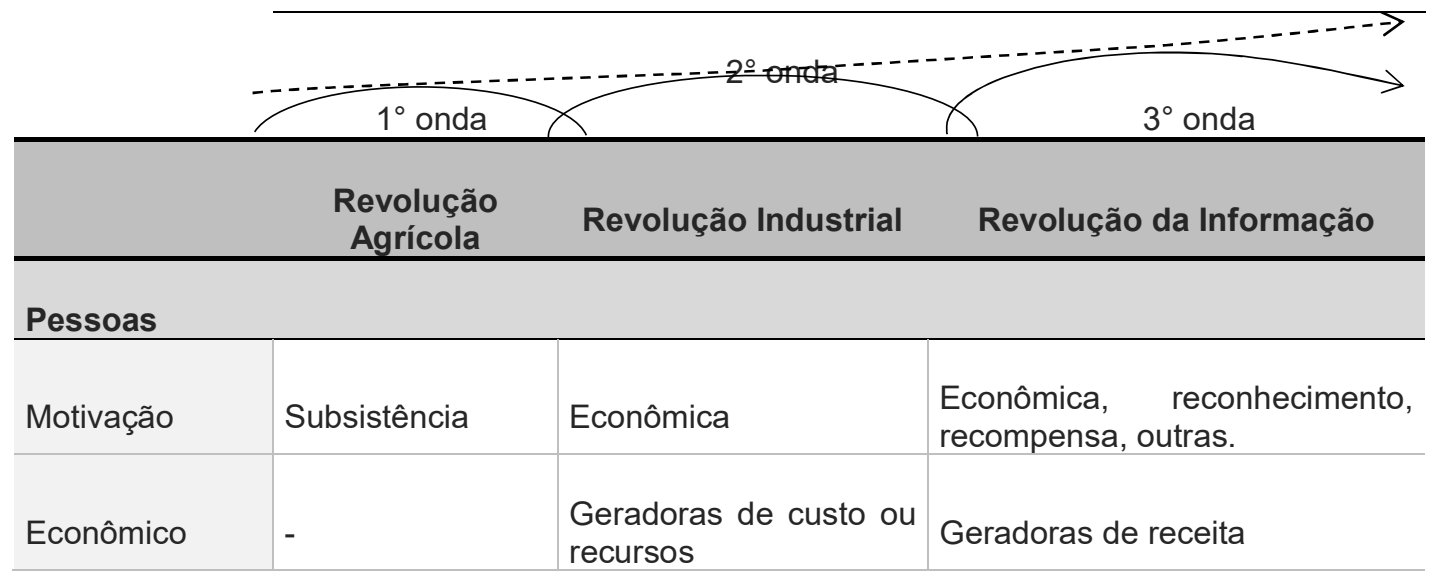

Inf. Inf., Londrina, v. 22, n. 1, p. 185 - 214, jan./abr., 2017. http:www.uel.br/revistas/informacao/ 
Fábio Corrêa, Jurema Suely de Araujo Nery Ribeiro, Marta Macedo Kerr Pinheiro Aspectos da economia da informação: arquétipo conceitual econômico e social

\begin{tabular}{|c|c|c|c|}
\hline Poder & $\begin{array}{l}\text { Proprietários de } \\
\text { terra }\end{array}$ & $\begin{array}{l}\text { Relativo na hierarquia } \\
\text { organizacional }\end{array}$ & Relativo ao conhecimento \\
\hline \multicolumn{4}{|l|}{ Produção } \\
\hline Processo & $\begin{array}{l}\text { Trabalho de } \\
\text { plantio e colheita } \\
\text { de produtos } \\
\text { consumíveis } \\
\text { tangíveis }\end{array}$ & $\begin{array}{l}\text { Trabalhadores físicos } \\
\text { processando recursos } \\
\text { físicos para criar } \\
\text { produtos tangíveis }\end{array}$ & $\begin{array}{l}\text { Trabalhadores } \\
\text { conhecimento, do } \\
\text { conhecimento em estruturas } \\
\text { intangíveis }\end{array}$ \\
\hline Trabalho & $\begin{array}{l}\text { Frequentemente } \\
\text { rotineiro }\end{array}$ & Rotineiro e padronizado & Dinâmico e desafiador \\
\hline Insumo & Terra & Capital & Informação e conhecimento \\
\hline Manifesto & Alimentos & $\begin{array}{l}\text { Produtos tangíveis } \\
\text { (hardware) }\end{array}$ & $\begin{array}{l}\text { Estruturas intangíveis (conceitos } \\
\text { e software) }\end{array}$ \\
\hline Forma & Produção manual & Produção em massa & $\begin{array}{l}\text { Produção } \\
\text { (personalização) orientada ao } \\
\text { cliente, com apoio de TICs. }\end{array}$ \\
\hline Fluxo & $\begin{array}{l}\text { Regido pelo } \\
\text { trabalho humano }\end{array}$ & $\begin{array}{l}\text { Regido pela máquina, } \\
\text { sequencial }\end{array}$ & Regido pelas ideias, caótico \\
\hline Tecnologia & $\begin{array}{l}\text { Ferramentas de } \\
\text { cultivo da terra }\end{array}$ & Máquinas & $\begin{array}{l}\text { Tecnologias de Informação e } \\
\text { Comunicação }\end{array}$ \\
\hline Força Motriz & $\begin{array}{l}\text { Atividade } \\
\text { humana, animal e } \\
\text { eólica }\end{array}$ & $\begin{array}{l}\text { Trabalho humano, } \\
\text { máquinas } \\
\text { combustível fóssil }\end{array}$ & $\begin{array}{l}\text { Trabalhador do conhecimento, } \\
\text { TICs e fontes de energias } \\
\text { diversas (fóssil, solar, eólica) }\end{array}$ \\
\hline \multicolumn{4}{|l|}{ Finanças } \\
\hline $\begin{array}{l}\text { Forma básica } \\
\text { de receita }\end{array}$ & Troca & Tangível (dinheiro) & $\begin{array}{l}\text { Intangível (aprendizado, novas } \\
\text { ideias, novos clientes, P\&D) }\end{array}$ \\
\hline $\begin{array}{l}\text { Relacionamento } \\
\text { com Cliente }\end{array}$ & - & $\begin{array}{l}\text { Unilateral pelos } \\
\text { mercados }\end{array}$ & Interativo pelas redes pessoais \\
\hline Efeito de porte & - & $\begin{array}{l}\text { Economia de escala na } \\
\text { produção }\end{array}$ & Economia de escopo das redes \\
\hline $\begin{array}{l}\text { Valor de } \\
\text { mercado }\end{array}$ & - & Ativos tangíveis & Ativos intangíveis \\
\hline Progresso & - & $\begin{array}{l}\text { Avanços tecnológicos } \\
\text { padroniza a produção e } \\
\text { leva ao progresso. }\end{array}$ & $\begin{array}{l}\text { Avanços tecnológicos não } \\
\text { trazem o progresso, mas são } \\
\text { vias para seu alcance. }\end{array}$ \\
\hline \multicolumn{4}{|l|}{ Organização } \\
\hline Informação & - & Instrumento de controle & Ferramenta para Comunicação \\
\hline Conhecimento & - & Ferramenta ou recurso & Foco empresarial \\
\hline
\end{tabular}

Inf. Inf., Londrina, v. 22, n. 1, p. 185 - 214, jan./abr., 2017. http:www.uel.br/revistas/informacao/ 
Fábio Corrêa, Jurema Suely de Araujo Nery Ribeiro, Marta Macedo Kerr Pinheiro Aspectos da economia da informação: arquétipo conceitual econômico e social

\begin{tabular}{|c|c|c|c|}
\hline $\begin{array}{l}\text { Fluxo } \\
\text { informacional }\end{array}$ & - & Hierárquico & Via redes colegiadas \\
\hline $\begin{array}{l}\text { Finalidade do } \\
\text { Aprendizado }\end{array}$ & $\begin{array}{l}\text { Uso no cultivo do } \\
\text { solo }\end{array}$ & $\begin{array}{l}\text { Aplicação de novas } \\
\text { ferramentas }\end{array}$ & Criação de novos ativos \\
\hline $\begin{array}{l}\text { Papel da } \\
\text { Gerência }\end{array}$ & - & $\begin{array}{l}\text { Supervisão } \\
\text { subordinados }\end{array}$ & Apoio aos colegas \\
\hline
\end{tabular}

Fonte: Adaptado de Toffler (1998), Crawford (1994), Pereira (1995) e Sveiby (1998).

Oportunamente ressalta-se que a indústria não findou a agricultura, bem como o conhecimento não o fará com a indústria, mas sim a transforma reduzindo sua relevância econômica em detrimento da economia emergente conseguinte. A agricultura continuará a fornecer nutrimentos aos viventes e a indústria perdurará na produção de produtos, entretanto a informação e o conhecimento assumem os pilares da economia do intangível. Com ênfase tem-se a convivência das eras em "países como o Brasil, no qual convivem três sociedades diferentes da Revolução Agrícola, da Revolução Industrial e uma minoria já vivenciando a nova Sociedade Pós-Industrial" (PEREIRA, 1995, p. 38).

A mudança do paradigma da tangibilidade não somente afeta a sociedade como também toda a economia. A Revolução Industrial causou consideráveis mudanças no campo e na cidade e a Revolução da Informação também o faz por diversos aspectos como as formas de trabalho (home office) e o perfil do trabalhador (físico para cerebral). A economia baseada em produtos físicos transcende para serviços e informação arraigada pela virtualidade.

Em tempo, torna-se representativo elucidar estas ondas de forma a consolidar os paradigmas que as constituem e as suplantam, evidenciando as rupturas econômicas e sociais decorrentes de tais evoluções (Erro! Fonte de referência não encontrada.).

Em primeira instância, a informação e o conhecimento sempre estiveram presentes na conformação das sociedades (DA CUNHA, 2003), entretanto ganham centralidade na economia dos intangíveis (LASTRES; ALBAGLI, 1999; VALENTIM, 2013). A Erro! Fonte de referência não encontrada. exprime aspectos das rupturas econômicas e sociais nas ondas da sociedade, 
Fábio Corrêa, Jurema Suely de Araujo Nery Ribeiro, Marta Macedo Kerr Pinheiro Aspectos da economia da informação: arquétipo conceitual econômico e social

distribuídos nas dimensões pessoas, produção, finanças e organização, sendo estes discutidos em sequência e ampliados com as dimensões ciência e mercado.

\subsection{DIMENSÕES DA ECONOMIA DA INFORMAÇÃO}

Esta seção discorre sobre rupturas econômicas e sociais nas ondas da sociedade, sendo tais rupturas abordadas sob a ótica de pessoas, produção, finanças e organização, e posteriormente ampliadas com as ciências e mercado, promovendo assim a denominação de seis dimensões.

\subsubsection{A Dimensão Pessoas}

Ao enfatizar que tais revoluções tiveram impactos na sociedade, a dimensão "pessoas" exprime algumas mudanças. A motivação das pessoas ao labor surge pela necessidade de subsistência na agricultura, sem ganhos econômicos, para uma necessidade de ganho de capital no industrialismo e se renova pela adição de reconhecimento e recompensa na economia do intangível.

O trabalhador, percebido como um custo anteriormente, agora é visto como uma potencial fonte de receita pelo seu conhecimento. Este novo perfil, denominado trabalhador do conhecimento, tornou-se um ativo organizacional. Stewart (1998) evidencia a ascendência deste perfil ao demonstrar um recorte de oitenta anos (1900 a 1980), no qual o número de operários de produção oriundos da indústria - foi reduzido em 39,2\% neste período, enquanto outros perfis, como técnicos e profissionais liberais, emergiam em 11,8\%.

Neste contexto, o salário não mais se apresenta como suficiente para reterem o trabalhador desta nova era. Este labutador do conhecimento espera receber não somente a remuneração representada pelo valor-hora, mas sim reconhecimento e recompensas. O capital de retorno de trabalho deve ser baseado nas habilidades e competência, e não mais no cargo que ocupa na empresa (PAIVA; MENDES, 2013).

Em verdade, os salários já não apresentam - ou pelo menos não deveriam - relação direta ao cargo ocupado na organização, mas sim ao conhecimento do indivíduo. O salário do trabalho repetitivo industrial foi amortizado diante do labor do trabalhador do conhecimento, uma vez que este 
Fábio Corrêa, Jurema Suely de Araujo Nery Ribeiro, Marta Macedo Kerr Pinheiro Aspectos da economia da informação: arquétipo conceitual econômico e social

tende a realização de sua função com maior eficiência (STEWART, 2007) devido ao conteúdo de seu conhecimento.

Por conseguinte, a relação de poder perpassa através das eras, sendo alterada da propriedade da terra para a hierarquia organizacional e se estabelece pelo conhecimento, não mais se restringindo ao domínio dos meios materiais (terra e estruturas políticas institucionais), mas ao controle do intangível pela informação e conhecimento (LASTRES; ALBAGLI, 1999).

\subsubsection{A Dimensão Produtiva}

Características produtivas sedimentam os processos que movimentam a economia das eras. A força motriz agrícola fundamentava-se no esforço de animais (plaustro, rodas d'agua, outros), eólica (barcos) e humano (músculo), com trabalho frequentemente rotineiro (tratar o solo, plantar e colher) no qual o fluxo de produção era regido pelo trabalho do homem (PEREIRA, 1995).

Em contraponto as características agrícolas, nas indústrias as máquinas produziam por meio de energia de combustão fóssil (carvão), padronizando o trabalho do homem - ainda muscular - e determinando sua rotina sequencial de ações para o desempenho das atividades produtivas fabris.

A era informacional rompe as características das eras anteriores. Diversas fontes de energia (fóssil, solar, eólica, outras) são utilizadas e o trabalhador do conhecimento (cérebro) apoia-se no uso das TICs para o desempenho de um labor dinâmico e desafiador que o motiva, no qual as ideias orientam o curso das atividades produtivas em um ambiente comumente caótico.

Enquanto o insumo dos processos produtivos da agricultura era a terra, na qual através de trabalho manual a produção se manifestava por meio de produtos alimentícios, nas indústrias o capital promovia a aquisição de bens para execução de processos fabris que resultavam em artigos tangíveis de uma produção massificada, sendo a informação e o conhecimento a base produtiva na atual economia, na qual o produto final resulta em estruturas intangíveis (conceitos e softwares) de um processo personalizado, orientado ao cliente, com apoio das TIC. 
Fábio Corrêa, Jurema Suely de Araujo Nery Ribeiro, Marta Macedo Kerr Pinheiro Aspectos da economia da informação: arquétipo conceitual econômico e social

A intangibilidade apresenta-se, nos processos das eras de evolução da sociedade, com um elemento abstrato do resultado das atividades das organizações. Observa-se na agricultura que os elementos terra, ferramentas de amanho e produtos alimentos são artigos palpáveis, bem como na indústria que manuseia recursos físicos (maquinas, aço, ferro, outros) para a produção de bens tangíveis.

$\mathrm{Na}$ sociedade do conhecimento o recurso informacional orienta as atividades, comumente desempenhada em computadores e softwares, resultando em produtos intangíveis como sistemas de informação para computadores, tablets e smartphones, que geram receitas as empresas por meio de produtos não palpáveis como oferta de seguros (vida e automóvel) e de serviços (tratamento e hospedagem da informação - datacenters).

De acordo com Petit (2005) os produtores tendem a ampliar suas relações com outras empresas, utilizando os serviços externos, a subcontratação, bem como alianças e acordos para acessar tecnologias e mercados ou para desenvolver inovações. Em verdade, as tecnologias apresentam-se como fatores determinísticos na economia e evolução da sociedade.

A Revolução Industrial foi marcada pela tecnologia do motor a vapor e produção por máquinas (PEREIRA, 1995), enquanto a Era da Informação pela tecnologia dos computadores (DRUCKER, 1999) fundamentando a evolução para a Era do Conhecimento (SAVAGE, 1996), que possui por alicerce as TIC.

Neste sentido, Gorz (2005) sugere que na economia do conhecimento o centro da criação de valor é o trabalho imaterial, pois "[...] tanto na produção industrial, quanto na produção de serviços, o trabalho passa a incorporar o capital imaterial, que pode ser qualificado como capital humano e capital conhecimento" (MARQUES; PINHEIRO, 2014, p. 3), valendo-se das TIC como promotora de circulação da informação e conhecimento.

\subsubsection{A Dimensão Finanças}

A ótica financeira diz respeito à constituição de valor, ou seja, o que é suscetível de produzir lucros as organizações. Na Era Industrial os investimentos de capital das empresas eram voltados para investimento em 
Fábio Corrêa, Jurema Suely de Araujo Nery Ribeiro, Marta Macedo Kerr Pinheiro Aspectos da economia da informação: arquétipo conceitual econômico e social

bens tangíveis como na agricultura (colheitadeiras, semeadeiras, tratores e pulverizadores), mineração (caminhões, carregadeiras, escavadeiras e perfuratrizes), petrolífero (motores, geradores, transmissores e bombas), construção (compactadoras, pavimentadoras, motoniveladoras e retroescavadeiras) e fabril (ferro, metal, aço e máquinas de tratamento e manipulação de materiais físicos).

Por outro lado, na Era da Informação as TIC assumem papel como meio para uma nova forma econômica. Stewart (1998) analisa os investimentos de empresas norte-americanas, no qual os dispêndios com TIC superam os relacionados a equipamentos de produção no ano de 1991. Para Corrado e Hao (2013) isto ocorre no ano de 1986, após avaliarem os investimentos de empresas no período de 1972 a 2011, evidenciando a superioridade de investimentos em intangíveis em relação aos bens físicos. Medrado et al (2016), em estudo recente, conclui que investimentos em ativos intangíveis possui relevância significativa no valor de mercado das empresas, ressaltando resultados dos investimentos identificados por Stewart (1998) e Corrado e Hao (2013).

Sveiby (1998) elucida que em 1995 as empresas de serviços obtiveram crescimento maior que a indústria, e ambos passaram a empregar o mesmo número de funcionários em 1998. Estes registros demonstram a extrusão da economia tangível para a economia do intangível, no qual o investimento elevase e a empregabilidade equipara-se com a economia dos bens físicos.

Tabela 1 - Número de empresas, pessoal ocupado e receita líquida do setor de Tecnologia da Informação e Comunicação - TIC - Brasil - 2003-2006

\begin{tabular}{|c|c|c|c|c|c|c|}
\hline \multirow{2}{*}{ Ano } & \multicolumn{2}{|c|}{ Empresas } & \multicolumn{2}{|c|}{ Pessoal ocupado } & \multicolumn{2}{|c|}{ Receita líquida (R\$) } \\
\hline & Número & $\begin{array}{r}\% \\
\text { Acumulado }\end{array}$ & Número & $\begin{array}{r}\% \\
\text { Acumulado }\end{array}$ & Valor & $\%$ Acumulado \\
\hline 2003 & 55.597 & $0,0 \%$ & 478.446 & $0,0 \%$ & $\mathrm{R} \$ 139.691 .700,00$ & $0,0 \%$ \\
\hline 2004 & 55.667 & $0,1 \%$ & 542.005 & $13,3 \%$ & $\mathrm{R} \$ 171.308 .628,00$ & $22,6 \%$ \\
\hline 2005 & 58.359 & $5,0 \%$ & 593.591 & $24,1 \%$ & $\mathrm{R} \$ 187.191 .402,00$ & $34,0 \%$ \\
\hline 2006 & 65.754 & $18,3 \%$ & 673.024 & $40,7 \%$ & $\mathrm{R} \$ 205.890 .414,00$ & $47,4 \%$ \\
\hline
\end{tabular}

Fonte: Adaptado de IBGE (2009)

Inf. Inf., Londrina, v. 22, n. 1, p. 185 - 214, jan./abr., 2017. http:www.uel.br/revistas/informacao/ 
Fábio Corrêa, Jurema Suely de Araujo Nery Ribeiro, Marta Macedo Kerr Pinheiro Aspectos da economia da informação: arquétipo conceitual econômico e social

No Brasil, o Instituto Brasileiro de Geografia e Estatística (IBGE) promoveu estudo sobre o setor de TIC e apresentou números que corroboram com os aspectos econômicos da economia da informação e do conhecimento. Segundo o IBGE (2009) o número de empresas que atuam no seguimento de TICs apresentaram aumento de $18,3 \%$ e elevação de $40,7 \%$ de pessoas lotadas entre 2003 e 2006, além de faturamento expressivo de $R \$ 205,9$ bilhões em 2006, representando um aumento de 47,4\% em relação ao ano de 2003 (Erro! Fonte de referência não encontrada.Erro! Fonte de referência não encontrada.).

Enquanto na indústria os avanços tecnológicos padronizavam a produção e promoviam economia de escala levando ao progresso pecuniário, na economia da informação tais avanços não necessariamente garantem tal progresso, mas atuam como meio para seu atingimento. O estudo do IBGE (2012) sobre o uso das TIC nas empresas brasileiras ratifica o potencial da tecnologia, uma vez que $25,6 \%$ das microempresas analisadas, de diversos seguimentos, efetuaram vendas e $41,1 \%$ e realizaram compras por meio da internet.

A estrutura da indústria demonstra as implicações de um novo princípio, com o estabelecimento de redes internacionais e a ocorrências de operações de fusões e aquisições. Assim, o setor financeiro rapidamente se transformou em um dos maiores usuários das TIC e em um dos mais globalizados por meio de parcerias operando em poucas, tradicionais e grandes praças financeiras (PETIT, 2005).

A forma básica de geração de receita na indústria foi, fundamentalmente, o capital - aquisição de bens tangíveis -, enquanto na economia da informação é o aprendizado, novas ideias, novos clientes, dentre outros intangíveis que promovem o conhecimento para a geração de retorno financeiro por meio das TIC, inovação e capital intelectual. Desta forma, o valor de mercado de uma empresa não mais se orienta pelos aspectos tangíveis, mas sim pelos intangíveis do capital intelectual, que se decompõe em capital humano (pessoas), estrutural (conhecimento empresarial, marca, patentes, outros) e de cliente (conhecimento e aliança com parceiros) (STEWART, 2007; SVEIBY, 1998). 
Fábio Corrêa, Jurema Suely de Araujo Nery Ribeiro, Marta Macedo Kerr Pinheiro Aspectos da economia da informação: arquétipo conceitual econômico e social

O estudo de Castro (2013) avaliou a diferença entre o valor de mercado e o valor contábil da empresa SADIA S.A., concluindo que "[...] a empresa vale mais de 14 vezes o seu valor contábil [...]" (CASTRO, 2013, p. 79), sendo esta diferença atribuída aos ativos intangíveis. Conforme Medrado et al (2016, p. 12), "a premissa é que a maior participação dos ativos intangíveis na estrutura patrimonial aumenta a perspectiva de geração de lucros anormais".

Por conseguinte, o capital de cliente, antes realizado por meio de relacionamento com o mercado, agora assume significância uma vez que é efetivado de forma interativa pelas redes de pessoas. Reconhecer os clientes pelo prisma do conhecimento (SVEIBY, 1998) é de vital relevância para que a empresa possa caminhar junto e orientada aos mesmos, elevando seu valor de mercado.

\subsubsection{A dimensão organizacional}

Diante da expressiva ruptura paradigmática decorrente da era informacional, as organizações tendem a uma nova forma de arranjo, significado e uso de recursos para que se adequem a este novo ambiente. A informação, antes percebida como um instrumento de controle, seja dos funcionários, seja de processos fabris e outros, sobrevêm como uma ferramenta de comunicação para equalização dos indivíduos à empresa. Neste sentido, a informação assume papel não somente de gestão, mas também como insumo comunicacional impreterível para um ambiente organizacional integrado que vise à conexão dos indivíduos para atingimento dos objetivos ambicionados pela empresa.

Para promover a integração dos indivíduos da empresa, o fluxo informacional hierárquico, orientado pelos níveis organizacionais, torna-se obsoleto e passa a ocorrer por meio das redes de pessoas - internas e externas - assumindo a forma de comunicação multidirecional (vertical e horizontal) na qual a informação flui em diversas direções na empresa. Neste sentido, o conhecimento deixa de ser percebido como uma ferramenta de uso nos processos contidos na organização e adquire significado mais amplo, como um ativo que se constrói pelo processo cognitivo do indivíduo sobre a informação (DAVENPORT; PRUSAK, 1998; CHOO, 2003; VALENTIM, 2013) e 
Fábio Corrêa, Jurema Suely de Araujo Nery Ribeiro, Marta Macedo Kerr Pinheiro Aspectos da economia da informação: arquétipo conceitual econômico e social

passa a ser o foco das empresas devido a sua relevância na economia da informação.

A função gerencial de supervisão é derrocada, uma vez que o contexto da empresa exprime amplitude que transcende o clássico processo de vigia das tarefas dos subordinados para um processo de apoio as atividades dos indivíduos (SVEIBY, 1998). A avaliação dos funcionários passa a ser realizada pelos resultados e não pelas tarefas realizadas e a gerência assume função de fomento a ação colaborativa entre os funcionários em prol do conhecimento (BUENO et al., 2004). Uma vez que o conhecimento se torna o foco organizacional, sugere-se então o surgimento do perfil de gerente do conhecimento (VON KROGH; ICHIJO; NONAKA, 2001; BUKOWITZ; WILLIAMS, 2002).

Assim, enquanto na era agrícola o aprendizado era voltado para o cultivo do solo e na era industrial para a aplicação e operacionalização de novas ferramentas, na era do conhecimento o aprendizado é norteado para a criação de novos ativos através do conhecimento compartilhado. Segundo Dupas (2005), as corporações tornam-se os sujeitos de direito mais importantes da sociedade civil, ao mesmo tempo em que suas decisões sobre padrões e vetores tecnológicos definem os produtos, que serão objetos de desejo, características do mercado de trabalho e da oferta de emprego, tornando-se os atores mais importantes da esfera política e do espaço público da sociedade liberal.

\subsubsection{A Dimensão Ciência}

\subsubsection{Ligação da Ciência da Informação e Computação na Economia da Informação}

Diante das mudanças de paradigmas, como precificação de bens e as rupturas elucidadas anteriormente, novas disciplinas são criadas de forma a promover entendimento e análises nos diversos contextos informacionais que passam a lidar com problemas de volume, armazenamento, recuperação e distribuição de informações.

Em 1949, Shannon e Weaver propuseram a Teoria da Informação (SHANNON; WEAVER, 2015) na qual um emissor comunica uma mensagem, que é codificada e posteriormente transmitida por um determinado canal, sendo 
Fábio Corrêa, Jurema Suely de Araujo Nery Ribeiro, Marta Macedo Kerr Pinheiro Aspectos da economia da informação: arquétipo conceitual econômico e social

posteriormente decodificada e destinada a um receptor. Enquanto a Teoria da Informação opera sob a forma de envio da informação, a Teoria da Comunicação atua sobre as significações da informação no processo de comunicação, abordando características e funções linguísticas (PERUZZOLO, 2015).

Conseguinte, a Ciência da Informação (Cl) "[...] tem por objeto o estudo das propriedades gerais da informação (natureza, gênese, efeitos), e a análise de seus processos de construção, comunicação e uso" (LE COADIC, 2004, p. 12), valendo-se de outras áreas do conhecimento para compreensão e ampliação da informação (DE ALBUQUERQUE FELL et al., 2014), tendendo ao uso da Teoria da Informação e Teoria da Comunicação (KOBASHI; TÁLAMO, 2003).

Desta forma, a $\mathrm{Cl}$ se consolida na Sociedade do Conhecimento em detrimento da relevância da informação e conhecimento, sendo estes elementos chave para as empresas. Neste âmbito as disciplinas de Gestão da Informação (GI) e Gestão do Conhecimento (GC), oriundas da $\mathrm{Cl}$, ganham espaço nas organizações.

A GI no contexto organizacional apresenta-se como um "[...] conjunto de conceitos, princípios, métodos e técnicas utilizados [...] para atingir a missão e os objetivos" (DIAS; BELLUZZO, 2003, p. 65) por meio do apoio ao processo de tomada de decisão (ESTENDER; BARBOSA; SANTOS, 2015). A GC pode ser compreendida como um processo integrado de criação, organização e disseminação do conhecimento, para atingimento de melhor desempenho da organização (DAVENPORT; PRUSAK, 1998; JARRAR, 2002; LEITE, 2006).

Haja vista que a informação é insumo para o conhecimento gerado por pessoas, Silva et al. (2011) argumenta que a o uso da Gl está imerso na GC, sendo aludido por Valentim (2014) ao ressaltar que a GI atua sobre o conhecimento explícito (documentado em meio físico ou digital), enquanto a GC possui por objeto o conhecimento tácito (existente no indivíduo), em um ciclo de alimentação e retroalimentação.

Assim, como a Cl se vale da Teoria da Informação e Comunicação, as TIC se amparam nestas teorias. O modelo de Shannon e Weaver (2015) está presente nos meios de comunicação computacionais, no qual o elemento 
Fábio Corrêa, Jurema Suely de Araujo Nery Ribeiro, Marta Macedo Kerr Pinheiro Aspectos da economia da informação: arquétipo conceitual econômico e social

emissor, receptor, sinal e meio de transmissão constituem a base das telecomunicações (TANENBAUM, 2011; LAUDON; LAUDON, 2010).

A Ciência da Computação possui a subárea específica de Recuperação da Informação, que consiste em acessar, organizar, armazenar e representar a informação permitindo facilidade de acesso aos usuários em meios como páginas web, catálogos online, dentre outros. As bibliotecas valem-se empiricamente desta subárea para consultas ao acervo por meio de sistemas de informação (BAEZA-YATES; RIBEIRO-NETO, 2013), bem como os periódicos acadêmicos eletrônicos.

Destarte, as TIC, a Cl e a GC se fundem em um arquétipo que permite o tratamento e representação da informação em forma e significado e seu compartilhamento na organização - interno e externo -, potencializando o uso da informação e conhecimento, estando ambas em constante discussão (VALENTIM, 2014), expansão literária (pesquisa) e mercadológica (softwares), fomentando a economia da informação na qual as empresas se valem destes recursos, científicos e tecnológicos, para aumento de lucratividade, melhor posicionamento competitivo, ou novas formas de ganhos, conforme abordado na dimensão mercado.

\subsubsection{A Dimensão Mercado}

\subsubsection{Modelos de Negócios e Receitas}

A economia da informação e do conhecimento está intimamente relacionada às TIC, assim como a indústria as máquinas. Os avanços tecnológicos promoveram formas de modelos de negócios e receitas que emergiram em virtude da internet, apresentando-se como meios de ganho pecuniário desta economia imaterial.

Modelos de negócios consistem no processo de geração de valor ao cliente no qual a empresa auferirá lucros financeiros em detrimento deste consumo (TEECE, 2010; CHESBROUGH, 2010; OSTERWALDER; PIGNEUR, 2011). Os modelos de negócios virtuais surgem como agregadores de valor a informação para consumo por meio da internet. Reforçar posições competitivas por meio de uma melhor capacidade de responder rapidamente às mudanças 
Fábio Corrêa, Jurema Suely de Araujo Nery Ribeiro, Marta Macedo Kerr Pinheiro Aspectos da economia da informação: arquétipo conceitual econômico e social

ambientais impõe a adoção de modelos de negócio adequados ao novo mundo dos negócios digitais (AL-DEBEl; AVISON, 2010).

A venda pela internet das empresas aos consumidores (B2C) possui as lojas virtuais como exemplo empírico de um modelo de negócio antes inconcebível. Enquanto as lojas físicas ofertam produtos com custos de operacionalização (translado de mercadorias) e de estoque, as lojas virtuais abrangem maior público (usuários da internet) atuando com baixo custo em tempo integral (LAUDON; LAUDON, 2010; RAINER JR; CEGIELSKI, 2011). Empresas como Walmart e Extra, e outras como a Amazon e Ebay, puramente virtuais (LAUDON; LAUDON, 2010, TIGRE; NORONHA, 2013) ilustram este processo de geração de valor.

As corretoras de transações apresentam-se como outro arquétipo. Empresas como Decolar.com e Trivago.com exemplificam este modelo, no qual ancoradas na praticidade de dispêndio de tempo e dinheiro ao cliente, realizam transações financeiras e recebem comissão por cada compra realizada (LAUDON; LAUDON, 2010).

Quadro 1 - Tipos de modelos de negócios virtuais

\begin{tabular}{|c|c|c|}
\hline Tipo & Descrição & Exemplo \\
\hline $\begin{array}{l}\text { Loja virtual (e-tailer) } \\
\text { ou Marketing direto } \\
\text { on-line }\end{array}$ & $\begin{array}{c}\text { Venda de produtos diretamente a } \\
\text { consumidores ou empresas } \\
\text { individuais }\end{array}$ & $\begin{array}{l}\text { lojasamericanas.com } \\
\text {.br } \\
\text {. } \quad \text { amazon.com }\end{array}$ \\
\hline $\begin{array}{l}\text { Corretora de } \\
\text { transações }\end{array}$ & $\begin{array}{c}\text { Geram comissões a cada compra } \\
\text { realizada }\end{array}$ & $\begin{array}{ll}\text { - } & \text { decolar.com } \\
\text { - } & \text { hotwire.com }\end{array}$ \\
\hline Criadores de mercado & $\begin{array}{c}\text { Ambiente no qual compradores e } \\
\text { vendedores determinam preços e } \\
\text { realizam vendas, como leilões, por } \\
\text { exemplo }\end{array}$ & $\begin{array}{c}\text { mercadolivre.com.br } \\
\text { ebay.com }\end{array}$ \\
\hline Provedor de conteúdo & $\begin{array}{l}\text { Provê conteúdo digital e fatura pelo } \\
\text { acesso a este ou por venda de } \\
\text { espaço para propaganda }\end{array}$ & $\begin{array}{c}\text { wsj.com } \\
\text { gettyimages.com }\end{array}$ \\
\hline $\begin{array}{l}\text { Provedor de } \\
\text { comunidade virtual }\end{array}$ & $\begin{array}{l}\text { Provê local onde as pessoas com } \\
\text { interesses semelhantes possam se } \\
\text { comunicar }\end{array}$ & $\begin{array}{l}\text { - } \quad \text { parperfeito.com.br } \\
\text { facebook.com }\end{array}$ \\
\hline Portal & $\begin{array}{l}\text { Ponto inicial de entrada na web } \\
\text { com oferta de conteúdo e serviços }\end{array}$ & $\begin{array}{l}\text { yahoo.com } \\
\text { google.com }\end{array}$ \\
\hline Provedor de Serviços & $\begin{array}{c}\text { Prove serviços compartilhamento } \\
\text { de arquivos (fotos e vídeos) e } \\
\text { armazenamento. }\end{array}$ & $\begin{array}{l}\text { dropbox.com } \\
\text { googleapps.com }\end{array}$ \\
\hline Grandes descontos & $\begin{array}{l}\text { Empresas oferecem grandes } \\
\text { descontos nos preços }\end{array}$ & $\begin{array}{c}\text { peixeurbano.com } \\
\text { half.com }\end{array}$ \\
\hline
\end{tabular}

Fonte: LAUDON; LAUDON (2010); RAINER JR; CEGIELSKI (2011). 
Fábio Corrêa, Jurema Suely de Araujo Nery Ribeiro, Marta Macedo Kerr Pinheiro Aspectos da economia da informação: arquétipo conceitual econômico e social

A iTunes.com e G1.com enquadram-se como provedores de conteúdo, uma vez que geram notícias, fotos e demais conteúdos e auferem receitas, dentre outros meios, pela venda de espaços em sua página para propaganda (LAUDON; LAUDON, 2010). Algumas tipologias de modelos de negócios podem ser visualizadas no Quadro 1.

Estes modelos de negócios possuem um ponto em comum: a informação. A Gettyimages.com comercializa imagens digitais, um bem da informação. Lojas virtuais tendem a oferecer produtos aos clientes de acordo com a informação de perfil e buscas realizadas no site. A base é a operacionalização, tratamento e recuperação da informação apoiada pelas TIC para geração de receitas.

As fontes de receitas representam o lucro que a empresa gera por cada seguimento de cliente (OSTERWALDER; PIGNEUR, 2011). Assim, na economia da informação uma empresa pode atuar em diversos seguimentos de clientes para aferir lucros, entretanto os modelos (formas) de receitas variam, sendo alguns tipos explicitados no Quadro 2.

Quadro 2 - Tipos de receitas em negócios virtuais

\begin{tabular}{|c|c|c|}
\hline Tipo & Descrição & Exemplo \\
\hline Propaganda & $\begin{array}{l}\text { Locação de espaço para exposição } \\
\text { de anúncio }\end{array}$ & $\begin{array}{c}\text { globo.com } \\
\text { descubraminas.com.br }\end{array}$ \\
\hline Venda & Comércio eletrônico & $\begin{array}{c}\text { - lojasamericanas.com } \\
\text { - pontofrio.com.br }\end{array}$ \\
\hline Assinatura & $\begin{array}{l}\text { Receita regular para acesso a } \\
\text { conteúdo ou serviços }\end{array}$ & $\begin{array}{ll}\text { - } & \text { TelecinePlay } \\
\text { - } & \text { Editora Abril }\end{array}$ \\
\hline Free/fremium & $\begin{array}{l}\text { Oferta de serviços e conteúdos } \\
\text { básicos e cobrança por } \\
\text { funcionalidades avançadas }\end{array}$ & $\begin{array}{l}\text { - } \quad \text { Dropbox } \\
\text { - } \quad \text { Locaweb }\end{array}$ \\
\hline Taxa de transação & Tarifação por transação & Pagseguro e Ebay \\
\hline $\begin{array}{c}\text { Modelo de afiliação, } \\
\text { ou Marketing } \\
\text { afiliado }\end{array}$ & $\begin{array}{l}\text { Redirecionamento ao site do } \\
\text { fornecedor para comissão sobre } \\
\text { vendas }\end{array}$ & $\begin{array}{l}\text { Modelo Google } \\
\text { Adsense }\end{array}$ \\
\hline
\end{tabular}

Fonte: LAUDON; LAUDON (2010); RAINER JR; CEGIELSKI (2011)

A propaganda consiste na exposição de anúncio assim, quanto mais acessos um site obtiver maior tende a ser seu público e consequentemente maior o valor para a inserção de propaganda, sendo a forma mais comum de geração de receita (RAINER JR; CEGIELSKI, 2011). Estima-se que em 2009, 
Fábio Corrêa, Jurema Suely de Araujo Nery Ribeiro, Marta Macedo Kerr Pinheiro Aspectos da economia da informação: arquétipo conceitual econômico e social

240 bilhões de dólares foram gastos com propaganda, sendo 10\% por meio online e os demais em rádios, televisão e jornais (LAUDON; LAUDON, 2010).

A receita por venda caracteriza-se pela comercialização de produtos, serviços ou informação (LAUDON; LAUDON, 2010). Lojas Americanas e Ponto Frio são alguns exemplos de venda de produtos (mercadorias) e informação (ebook) no Brasil, assim como a base Emerald com a venda de artigos científicos, o iTunes com músicas e a Crivo Transunion com a oferta de serviços de birô de informações.

As assinaturas garantem receita regular para acesso a conteúdo ou serviços (LAUDON; LAUDON, 2010), sendo exemplificados por serviços de conteúdo e programação televisiva portátil como GloboPlay e TelecinePlay (Grupo Globo), Editora Abril e Folha de São Paulo no seguimento de revistas e jornais, respectivamente.

Entretanto, algumas estratégias são adotadas como a free/fremium, no qual são ofertados serviços e conteúdos básicos e cobrados funcionalidades avançadas (LAUDON; LAUDON, 2010) como o serviço de armazenamento do DropBox e construtor de sites como Wix, Webnode e Locaweb, objetivando assim que o usuário se torne assinante após desfrutar e conhecer os recursos básicos.

Outro tipo é taxa por transação, que obtém receita por meio de tarifação sobre determinada transação. O PagSeguro e eBay atuam neste segmento ao executarem transações financeiras e cobrarem valores sobre as mesmas. $O$ modelo de afiliação (LAUDON; LAUDON, 2010), ou marketing afiliado (RAINER JR; CEGIELSKI, 2011), apresenta-se como outra forma de receita que resulta na divulgação de um link (banner, logotipos e, ou, textos) no site afiliado que direciona o usuário ao site do fornecedor, no qual as compras efetivadas em detrimento desta ligação resultam em comissões ao afiliado, sendo o Google Adsense um modelo empírico desta forma de receita (TIGRE; NORONHA, 2013).

\subsubsection{Precificação na Economia da Informação e do Conhecimento}

No início da Revolução Industrial - século XVIII - a contabilidade financeira supria os cálculos de custos basicamente fundamentados em matéria prima e mão de obra (MARTINS, 2003; CREPALDI, 2009), mas com o 
Fábio Corrêa, Jurema Suely de Araujo Nery Ribeiro, Marta Macedo Kerr Pinheiro Aspectos da economia da informação: arquétipo conceitual econômico e social

surgimento das máquinas a complexidade de cálculo dos custos de fabricação se alterou, dando origem a disciplina de contabilidade de custos. Por meio da contabilidade de custos, a fixação de preços pode ser fundamentada nos custos de produção unitário do produto ao qual é adicionada uma margem de lucro para formar o preço de venda (SINGER, 2002; CREPALDI, 2009).

A UOL (Universo OnLine) estratifica a tabela de preços de acordo com alguns parâmetros como segmentação de canal (homepage, mobile, rádio, outros), tamanho de banner, formato e dia da semana, variando de $\mathrm{R} \$ 0,07$ a $\mathrm{R} \$ 308.000,00$ (UOL, 2016). O preço de venda de um bem da informação corrompe um paradigma sedimentado há séculos na economia industrial.

Considere a fabricação de uma mesa de escritório em madeira pela empresa fictícia ArtMoveis. Para fins ilustrativos, o preço de aquisição da madeira, de mão de obra e demais insumos para a produção desta (parafusos, artigos de aderência, dentre outros) somados a impostos resulta, simplificadamente, no custo de produção deste móvel. Analisando o custo unitário de produção a ArtMóveis conclui que cada mesa tem o custo de $\mathrm{R} \$ 100,00$ e adiciona margem de lucro de $60 \%$, resultando no preço de venda de $R \$ 160,00$.

O exemplo da ArtMoveis explicita que a cada mesa fabricada haverá o custo de produção de $R \$ 100,00$, entretanto na economia da informação esta relação de custo de produção e precificação não funciona, pois os custos da segunda cópia são ínfimos (SHAPIRO; VARIAN, 2009; LAUNDON; LAUNDON, 2010).

Contrapondo o exemplo da ArtMoveis considere, hipoteticamente, a empresa eGames. A eGames identificou um nicho de mercado de um milhão de clientes para criação de um novo jogo e iniciou o projeto. Roteiristas, designers, programadores, equipamentos, licenças de softwares, entre outros recursos foram alocados e adquiridos para a construção do jogo. Ao final de 10 meses o projeto foi concluído com o custo total de $\mathrm{R} \$ 500$ mil.

Os produtos das empresas ArtMóveis e eGames se distinguem pela intangibilidade, não permitindo a aplicação das mesmas lógicas sobre os produtos. Primeiramente, o preço da segunda cópia do jogo produzido pela eGames é irrisório uma vez que se ocorrer via compact disk (CD) o custo será, 
Fábio Corrêa, Jurema Suely de Araujo Nery Ribeiro, Marta Macedo Kerr Pinheiro Aspectos da economia da informação: arquétipo conceitual econômico e social

praticamente, o valor do CD (menos de $R \$ 1,00$ ), entretanto se ocorrer por meio de redes digitais (internet) será praticamente zero, diferentemente da ArtMóveis, no qual a cada novo móvel produzido o custo unitário é aferido.

Figura 2 - Precificação e versões da informação

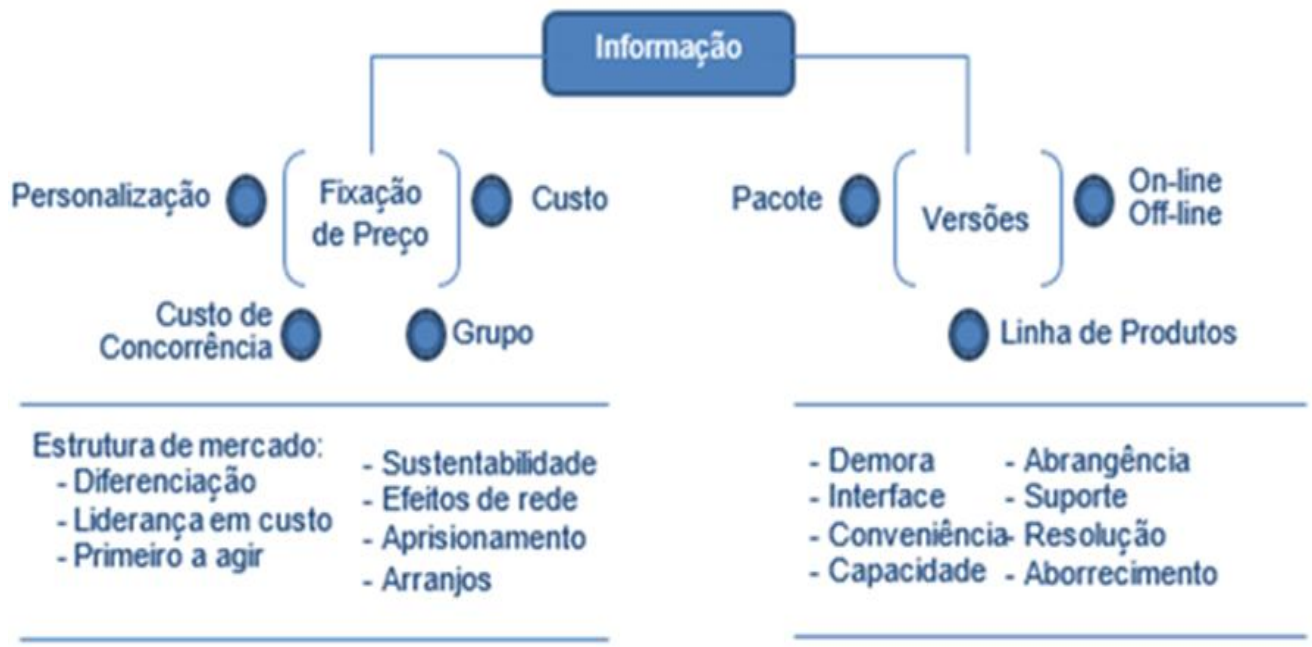

Fonte: Adaptado de Shapiro; Varian (1999)

Desta forma, a precificação do jogo da eGames difere da ArtMóveis. Aplicar a margem de lucro sobre o custo unitário da cópia resultaria em valores próximos ao do $\mathrm{CD}$, ou próximos de zero considerando o uso de redes digitais. Assim, as formas de precificação não seguem os padrões econômicos da indústria, mas sim os da economia da informação.

Shapiro \& Varian (1999) ponderam diversos aspectos da economia da informação, dentre eles algumas características de fixação de preços e versões da informação, conforme elucidado pela Figura 2, no qual a fixação de preços contempla aspectos de personalização da informação, custo de concorrência, grupos e custos, enfatizando elementos balizadores de precificação, bem como a criação de versões de informação que permite distinguir os produtos informacionais e, consequentemente, seu valor ao cliente.

Com ênfase, tem-se que artigos intangíveis possuem características inerentes e divergentes dos produtos industriais (físicos) e tais características promovem contínuas ponderações que permitem avanços no comportamento das organizações no mercado da economia da informação. 
Fábio Corrêa, Jurema Suely de Araujo Nery Ribeiro, Marta Macedo Kerr Pinheiro Aspectos da economia da informação: arquétipo conceitual econômico e social

\section{$3 \quad$ RESULTADOS}

O comportamento dos agentes econômicos, que surgiu e está alcançando uma massa crítica, segundo Evans \& Wurster (2000), pode ser considerado o cerne da mudança com a economia da informação não representando especificamente tecnologia.

A preocupação com o uso da informação nos negócios é um objeto de estudo acadêmico há algum tempo. Acredita-se que a organização baseada no conhecimento é o modelo de organização do futuro fundamentada no aparato cognitivo formado por especialistas (DRUCKER, 1999).

As transformações organizacionais, oriundas da Revolução da Informação, traz a necessidade do uso adequado das informações para que as organizações consigam vantagens competitivas. Porter \& Millar (1985) afirmam que tais vantagens podem ser obtidas através de reduções de custos, processamento e transmissão de informações, bem como a geração de novas formas de negócios.

Em consonância com a Revolução da Informação, as TIC alicerçam esta era informacional e são resultado da evolução das Ciências da Informação e da Computação, de forma que respondem por avanços e insumos presentes na economia pautada no intangível.

A economia da informação requer organizações proativas na constante busca da inovação. Os sistemas de informações precisam ser flexíveis de modo que suportem modificações de produtos, de processos e da própria organização. O uso da informação e do conhecimento proporciona novos tipos de produtos, serviços, e modelos de negócios.

Com o intuito de elucidar a discussão deste estudo, a Figura 3 apresenta uma visão de aspectos da economia da informação que aborda elementos de extrusão, representados pelas dimensões produção, pessoas, finanças e organização, bem como as dimensões ciência e mercado que complementam o arquétipo conceitual de aspectos que compõem a economia da informação.

A Figura 3 tem a Economia da Informação como elemento central, circundada pela informação e conhecimento e por aspectos que representam extrusões das economias anteriores e exterioridades relacionadas à economia do intangível. 
Fábio Corrêa, Jurema Suely de Araujo Nery Ribeiro, Marta Macedo Kerr Pinheiro Aspectos da economia da informação: arquétipo conceitual econômico e social

Os aspectos produção, pessoas, finanças e organização representam características abordadas pela economia do intangível, amparadas pela literatura de autores como Toffler (1998), Crawford (1994), Pereira (1995) e Sveiby (1998).

Figura 3 - Arquétipo conceitual de aspectos da economia da informação

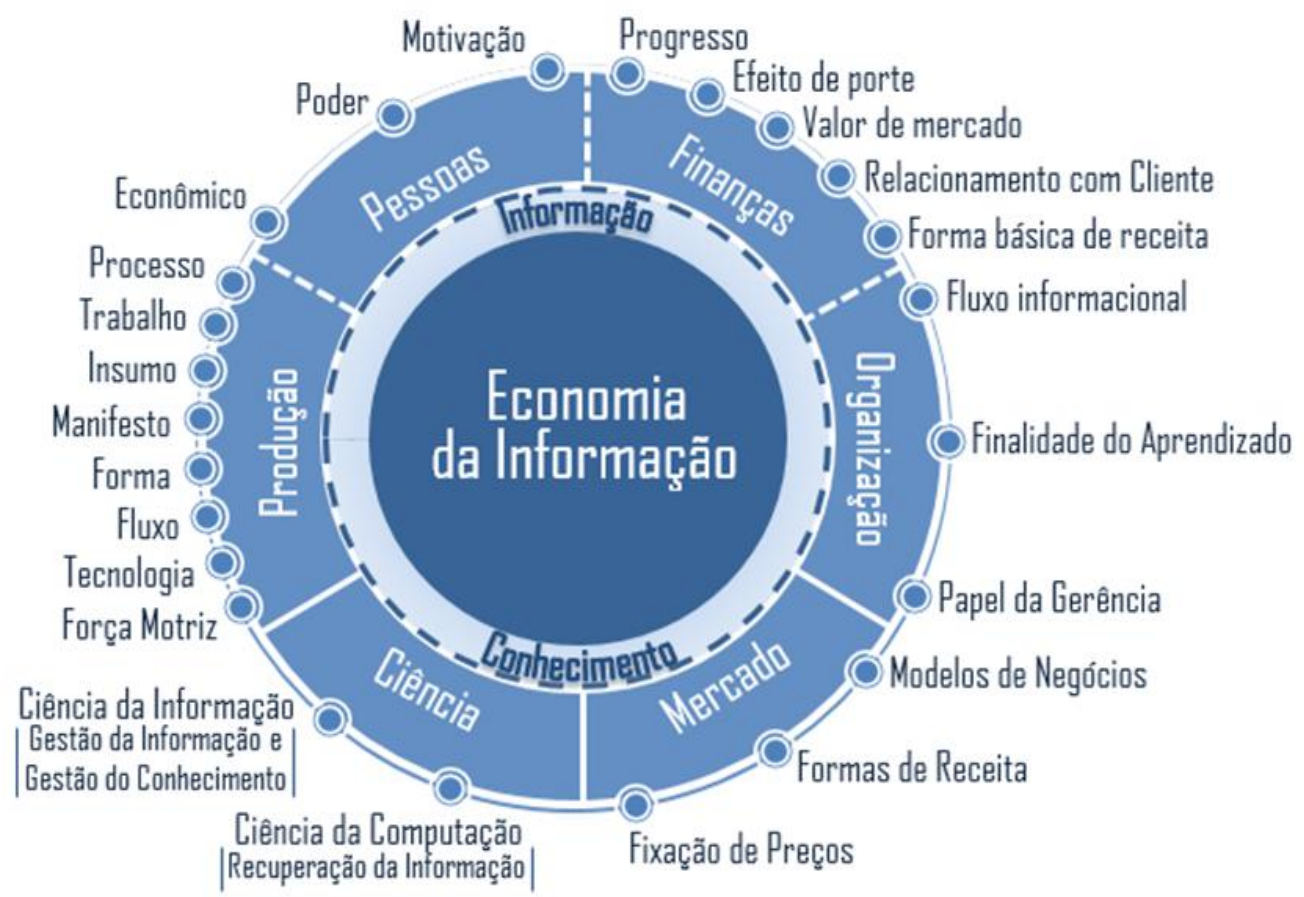

Fonte: Elaborado pelos autores, 2016.

As exterioridades ciência e mercado abarcam elementos constituintes da economia do imaterial, que se apresentam como particularidades de uma economia alicerçada nos elementos de intangibilidade.

Diante dos impactos na sociedade e economia, é razoável inferir que as ciências voltadas para a informação e conhecimento tendem a crescente evolução uma vez que promovem contribuições acadêmicas (pesquisas) e fomentam modelos e processos organizacionais no que tange a gestão da informação e do conhecimento. 
Fábio Corrêa, Jurema Suely de Araujo Nery Ribeiro, Marta Macedo Kerr Pinheiro Aspectos da economia da informação: arquétipo conceitual econômico e social

\section{CONSIDERAÇÕES FINAIS}

Em um ambiente de rápidas transformações e novos tipos de negócios muito se discute a respeito da economia do imaterial. A principal característica seria a crescente ascendência da quantidade de informações a serem processadas por uma organização quando comparada ao montante que se processava no passado. A internet e a possibilidade de realizar negócios de formas diversas fizeram surgir uma preocupação quanto ao processamento de informações necessárias à tomada de decisões no ambiente de negócios da empresa

Este estudo discorreu sobre alguns aspectos da sociedade pósindustrial, na qual a intangibilidade se sobrepõe a tangibilidade. Neste contexto, as rupturas na forma de trabalho, sociedade, finanças, organizações, e surgimento de modelos de negócios e receitas, refletem a relevância da informação e do conhecimento nesta sociedade.

Acredita-se que este artigo possa contribuir para a compreensão e reflexão dos aspectos desruptivos apresentados no arquétipo conceitual da Figura 3 (produção, pessoas, finanças, organização, ciência e mercado) relacionado à economia da informação, por meio da comparação com as eras da sociedade, oferecendo assim uma visão ampliada sobre esta economia.

Em tempo, salienta-se que este estudo não teve o propósito de abranger a totalidade dos aspectos desta economia do intangível, haja vista que seria equivocado ambicionar algo de tamanha amplitude, bem como não contempla alguns elementos como inovação, estratégia, inteligência, dentre outros, o que permite o surgimento de novas proposições que possam complementar este arquétipo conceitual.

\section{REFERÊNCIAS}

AL-DEBEI, M. M; AVISON, D. Developing a unified framework of the business model concept. European Journal of Information Systems, v.19, p. 359-376, 2010.

ANGELONI, M. T.; FERNANDES, C. B. Organizações de conhecimento: dos modelos à aplicação prática. In: Encontro de Estudos Organizacionais ENEO, Curitiba/PR, 2000. Anais... Curitiba: GEO/ANPAD, 2000. 
Fábio Corrêa, Jurema Suely de Araujo Nery Ribeiro, Marta Macedo Kerr Pinheiro Aspectos da economia da informação: arquétipo conceitual econômico e social

BAEZA-YATES, R.; RIBEIRO-NETO, B. Recuperação de informação: conceitos e tecnologia das máquinas de busca. Bookman, 2013.

BELL, D. et al. The corning of post-industrial society. New York, 1973.

BUENO, G. S. et. al. Gestão estratégia do conhecimento. Revista FAE, v. 7, n. 1, p. 89-102, 2004.

BUKOWITZ, W. R.; WILLIAMS, R. L. Manual de gestão do conhecimento:

ferramentas e técnicas que criam valor para a empresa. São Paulo: Bookman, 2002. CASTELLS, M. A sociedade em rede: a era da informação: economia, sociedade e cultura. 10. ed. São Paulo: Paz e Terra, 2007.

CASTRO, W. B. O Impacto das restrições para registro dos ativos intangíveis na diferença entre o valor de mercado o valor contábil. Revista Brasileira de Contabilidade, n. 215. 2013.

CHESBROUGH, H. Business Model Innovation: opportunities and barriers. Long range lanning, v. 43, n. 2- 3, p. 354-363, Apr-Jun 2010.

CHOO, C. W. A organização do conhecimento. São Paulo: Senac, 2003.

CORRADO, C. A.; HAO, J. X. Economic research working paper, n. 13, 2013.

COSTA, A. F.; COSTA, M. F. B. Metodologia da pesquisa: conceitos e técnicas. Rio de Janeiro: Interciência, 2001.

CRAWFORD, R. Na era do capital humano: o talento, a inteligência e o conhecimento como forças econômicas; seu impacto nas empresas e nas decisões de investimento. São Paulo: Atlas, 1994.

CREPALDI, S. A. Curso básico de contabilidade de custos. 4. ed. São Paulo: Atlas, 2009.

DA CUNHA, V. A. A biblioteca pública no cenário da sociedade da informação.

Biblios: Revista electrónica de bibliotecología, archivología y museología, n. 15, p. 7, 2003.

DAVENPORT, T. H; PRUSAK, L. Conhecimento empresarial: como as organizações gerenciam o seu capital intelectual. 11. ed. Rio de Janeiro: Campus, 1998.

DIAS, M. M. K; BELLUZZO, R. C. B. Gestão da informação em ciência e tecnologia sob a ótica do cliente. Bauru: EDUSC, 2003.

DRUCKER, T. F. Sociedade pós-capitalista. Rio de Janeiro. 1999.

DUPAS, G. Assimetrias e impasses na nova lógica do poder global. In: DUPAS, G. Atores e poderes na nova ordem global: assimetrias, instabilidades e imperativos de legitimação. São Paulo: UNESP, Cap.1, p.15-80, 2005.

ESTENDER, A. C.; BARBOSA, L. O. S.; SANTOS, D. P. Gestão da informação: a comunicação interna nas empresas. Revista de Administração da Fatea, v. 11, n. 11, 2015. 
Fábio Corrêa, Jurema Suely de Araujo Nery Ribeiro, Marta Macedo Kerr Pinheiro Aspectos da economia da informação: arquétipo conceitual econômico e social

EVANS, P. B.; WURSTER, T. S. A explosão dos bits: blown to bits. Rio de Janeiro: Campus, 2000.

FELL, A. F. A, et. al. A Produção Acadêmica no Brasil sobre Ciência da Informação: um estudo a partir da Teoria do Conhecimento de Habermas. Em Questão, v. 20, n. 1, p. 127-150, 2014.

GIL, A. C. Métodos de pesquisa social. São Paulo: Atlas, 1999.

GORZ, A. O imaterial, conhecimento, valor e capital. São Paulo: Annablume, 2005.

HOBSBAWM, E. A era das revoluções: 1789-1848. Editora Paz e Terra, Kindle Edition, 2015.

IBGE - Instituto Brasileiro de Geografia e Estatística. O setor de tecnologia da informação e comunicação no Brasil 2003, 2006, 2009.

IBGE - Instituto Brasileiro de Geografia e Estatística. Pesquisa sobre o uso das tecnologias da informação e comunicação nas empresas 2010, 2012.

JARRAR, Y. F. Knowledge management: learning for organizational experience. Managerial Auditing Journal, Melbourne, v. 17, n. 6, p. 322-328, 2002.

KOBASHI, N. Y.; TÁLAMO, M. F. G. M. Informação: fenômeno e o objeto de estudo da sociedade contemporânea. Transinformação, v. 15, n. 3, 2003.

LASTRES, H. M. M.; ALBAGLI, S. Chaves para o Terceiro Milênio na Era do Conhecimento. In: LASTRES, H. M. M.; ALBAGLI, S. (Org.). Informação e globalização na era do conhecimento. Rio de Janeiro: Campus, 1999.

LAUDON, K. C.; LAUDON J. P. Sistemas de informação gerenciais. 9. ed. São Paulo: Prentice Hall, 2010.

LE COADIC. A ciência da informação. Brasília: Briquet de Lemos, 2004.

LEITE, F. C. L. Gestão do conhecimento científico no contexto acadêmico: proposta de um modelo conceitual. Brasília. 2006, 240 f. Dissertação (Mestrado em Ciência da Informação) - Programa de Pós-graduação em Ciência da Informação, Universidade de Brasília, Brasília, 2006.

LÉVY, P. As tecnologias da inteligência. São Paulo: Cibercultura, 2001.

MARQUES, R. M.; PINHEIRO, M. M. K. Polarização do conhecimento na era da informação: o Vale do Silício como exemplo. Tendências da Pesquisa Brasileira em Ciência da Informação, v. 7, n. 1, 2014.

MARTINS, E. Contabilidade de custos. 9. ed. São Paulo: Atlas, 2003.

MEDRADO, F. et al. Relação entre o nível de intangibilidade dos ativos e o valor de mercado das empresas. Revista de Contabilidade e Organizações, n. 28, p. 32-44, 2016. 
Fábio Corrêa, Jurema Suely de Araujo Nery Ribeiro, Marta Macedo Kerr Pinheiro Aspectos da economia da informação: arquétipo conceitual econômico e social

OSTERWALDER, A.; PIGNEUR, Y. Business model generation - inovação em modelos de negócios: um manual para visionários, inovadores e revolucionários. Alta Books, 2011.

PAIVA, A. M. L.; MENDES, J. F. S. Dinâmica do emprego, remuneração e produtividade na economia do consumo. Economia \& Empresa. Lisboa, n. ${ }^{\circ}$ 16, 2013.

PEREIRA, H. J. Os novos modelos de gestão: análise e algumas práticas em empresas brasileiras. São Paulo: FGV, 1995, 297 f. Tese (Doutorado em Administração de Empresas) - Programa de Pós-graduação em Administração de Empresas, Fundação Getúlio Vargas, São Paulo, 1995.

PEREZ, M. M.; FAMÁ, R. Características estratégicas dos ativos intangíveis e o desempenho econômico da empresa. Unisanta Law and Social Science, v. 4, n. 2, p. 107-123, 2015.

PERUZZOLO, A. C. Elementos de semiótica da comunicação. Paco Editorial, 2015.

PETIT, P. Estrutura e desenvolvimento de uma economia baseada no conhecimento: implicações para políticas. In; LASTRE, H. M. M.; CASSIOLATO, J. E; ARROIO, A.(Org.). Conhecimento, sistemas de inovação e desenvolvimento. Rio de Janeiro: UFRJ/Contraponto, 2005. Cap.4, p.131-160.

PORTER, M. E. ; MILLAR, V. E. How information gives you competitive advantage. Harvard Business Review, Jul./ Ago.1985.

PREVEDELLO, C. F.; ROSSI, W. S.; ROCHA COSTA, A. C. Direito autoral na produção de materiais didáticos para a educação à distância: reflexões para a utilização na era da informação. Thema, v. 12, n. 2, p. 26-39, 2015.

RAINER JR, K. R.; CEGIELSKI, C. G. Introdução aos sistemas de informação: apoiando e transformando negócios na era da mobilidade. São Paulo: Altas, 2011.

SAVAGE, C. M. Geração de gerência: criando por meio do empresariamento do virtual, do dinamismo das equipes e do conhecimento colocado em rede. Pioneira, 1996.

SETZER, V. W. Dado, Informação, Conhecimento e Competência. DataGramaZero. n. zero dez/99.

SILVA, W. P. et al. O Processo de avaliação de demandas da rede de pesquisa e inovação em tecnologias digitais. In: XVIII Simpósio de Engenharia de Produção SIMEP, Bauru/SP, 2011. Anais... São Paulo: SIMEP, 2011.

SHAPIRO, C.; VARIAN, H. R. A economia da informação: como os princípios econômicos se aplicam à era da internet. Rio de Janeiro: Campus, 2013.

SHANNON, C. E.; WEAVER, W. The mathematical theory of communication. University of Illinois Press, 2015.

SINGER, P. O que é economia. São Paulo: Contexto, 2002.

STEWART, T. A. Capital intelectual: a nova vantagem competitiva das empresas. Rio de Janeiro: Campus, 1998. 
Fábio Corrêa, Jurema Suely de Araujo Nery Ribeiro, Marta Macedo Kerr Pinheiro Aspectos da economia da informação: arquétipo conceitual econômico e social

STEWART, T. A. The wealth of knowledge: Intellectual capital and the twenty-first century organization. Crown Business, 2007.

SVEIBY, K. E. A nova riqueza das organizações: gerenciando e avaliando patrimônios do conhecimento. 5. ed. Rio de Janeiro: Campus, 1998.

TANENBAUM, A. S. Redes de computadores. 5. Ed. São Paulo. Campus, 2011.

TEECE, D. J. Business models, business strategy and innovation. Long Range Planning, v. 43, n. 2-3, p. 172- 194, Apr-Jun 2010.

TIGRE, P. B.; NORONHA, V. B. Do mainframe à nuvem: inovações, estrutura industrial e modelos de negócios nas tecnologias da informação e da comunicação.

Revista de Administração, São Paulo, v. 48, n. 1, p. 114-127, 2013.

TINOCO, J. E. P. Gestão de recursos humanos: uma abordagem contábil no contexto da gestão do Conhecimento. eGesta - Revista Eletrônica de Gestão de Negócios, v. 1, n. 1, Apr-Jun, p. 83-104, 2005.

TOFFLER, A. A terceira onda. São Paulo: Atlas, 1998.

TURBAN, E.; LEIDNER, D.; MCLEAN, E.; WETHERBE, J. Tecnologia da informação para gestão. 6. ed., Porto Alegre: Bookman, 2010.

UOL - Universo OnLine. Tabela de preços - Janeiro 2016. Disponível em:

<http://download.uol.com.br/publicidade/Publicidade.pdf>. Acesso em: 30 mai. 2016.

VALENTIM, M. L. P. (org). Gestão da informação e do conhecimento no âmbito da ciência da informação. São Paulo: Polis: Cultura Acadêmica. 2013.

VALENTIM, M. L. P. Gestão da informação e gestão do conhecimento em ambientes organizacionais: conceitos e compreensões. Tendências da Pesquisa Brasileira em Ciência da Informação v. 1, n. 1, 2014.

VON KROGH, G; ICHIJO, K; NONAKA, I. Facilitando a criação de conhecimento: reinventando a empresa com o poder da inovação contínua. Rio de Janeiro: Campus, 2001.

\section{Title}

Aspects of the information economy: conceptual economic and social archetype

\section{Abstract:}

Introduction: Companies have undergone significant changes coming from evolutionary paradigms supported by technological and informational aspects, which have resulted in various changes making the organisations environment, internal and external, complex, due to the intricate pattern disruption in the evolution of society, in which information, competition and technology have decisive action. Objective: This study aimed to promote a reflection on the aspects of the information economy that determine this new society, guided by the problem: which subversive aspects based the information economy? Methodology: This is an exploratory research, once it looks for a dilated optical of the information economy, in order to provide understanding and 
Fábio Corrêa, Jurema Suely de Araujo Nery Ribeiro, Marta Macedo Kerr Pinheiro Aspectos da economia da informação: arquétipo conceitual econômico e social

reflection on subversive aspects; and descriptive since it aims to elucidate, through the analysis and interpretation of the facts, the dimensions of the information economy. Results: As a result it was proposed a conceptual archetype of the disruptive aspects of the information economy, represented by the dimensions, production, people, finance, organization, science and market. Conclusion: It is concluded that this study tends to contribute to understanding and reflection of the aspects related to the information economy, through comparison with the ages of society, thus offering an extended vision of this economy.

Keywords: Information economy. Knowledge economy. Subversive aspects. Conceptual archetype.

\section{Titulo}

Aspectos de la información económica: arquetipo conceptual económico y social

\section{Resumen:}

Introducción: Las empresas han experimentado cambios significativos resultantes de paradigmas evolutivos apoyados por los aspectos tecnológicos y de información, lo que provocó varios cambios haciendo el ambiente, interno y externo, de las organizaciones complejas, debido a los patrones de ruptura intrincados en la evolución de la sociedad, en el que información, competencia y tecnología tienen un papel determinante. Objetivo: Este estudio tuvo como objetivo promover una reflexión sobre los aspectos de la economía de la información que determinan esta nueva sociedad, guiando por el problema: ¿qué subvertedores aspectos que se basa la economía de la información? Metodología: Se trata de una investigación exploratoria, para buscar una perspectiva más amplia de la economía de la información, para proporcionar comprensión y reflexión sobre sus aspectos subversivos; y descriptivo en el objetivo de dilucidar, para el análisis y la interpretación de los hechos, las dimensiones de la economía de la información .Resultados: Con el resultado se propuso un arquetipo conceptual de los aspectos subvertedores de la economía de la información, representada por las dimensiones producción, gente, finanzas, organización, ciencia y mercado. Conclusión: Se concluye que este estudio tiende a contribuir a la comprensión y la reflexión de los aspectos relacionados con la economía de la información, en comparación con las edades de la sociedad, proporcionando una visión amplia de esta economía.

Palabras clave: Economía de la información. Economía del conocimiento. Aspectos subvertedores. Arquetipo conceptual.

Recebido: 12.02 .2016

Aceito: 25.03.2017 